Trabajos y Comunicaciones, 2da. Época, No 47, e050, enero-junio 2018. ISSN 2346-8971

Universidad Nacional de La Plata.

Facultad de Humanidades y Ciencias de la Educación.

Departamento de Historia

\title{
"No debemos abdicar de todo lo que ha avanzado la reflexión histórica en aras de la popularidad": dinámicas historiográficas, relatos y contrarrelatos en España. Una entrevista a Juan Pan- Montojo*
}

\author{
Gabriel Fernando Carini
}

Centro de Investigaciones Históricas de la Universidad Nacional de Río Cuarto (CIH-UNRC) Centro de Investigaciones de la Facultad de Filosofía y Humanidades de la Universidad Nacional de Córdoba (CIFFyH-UNC)

Consejo Nacional de Investigaciones Científicas y Técnicas (CONICET), Argentina gabrielcarini@hotmail.com

Juan Pan-Montojo (1962) es Licenciado en Filosofía y Letras y en Ciencias Económicas y doctor en Historia Contemporánea por la Universidad Autónoma de Madrid. Ha efectuado estancias de investigación en la London School of Economics and Political Sciences (Londres, Reino unido), en el Center for Historial Studies de la New school for Social Research (Nueva York, EE.UU.) y en la Friedrich-Alexander Universität of Erlangen-Nürnberg (Alemania) y estancias docentes y de investigación en la Universidad de la República (Montevideo, Uruguay) y en la Écoles des Hautes Études en Sciences Sociales (París, Francia). En la actualidad es Profesor Titular de Historia Contemporánea de la Universidad Autónoma de Madrid. Ha coordinado el grupo de trabajo sobre "Estados, instituciones y legislación” de la Red de Excelencia Europea Cliohres y participado en dieciséis proyectos de investigación nacionales. Actualmente dirige el proyecto nacional "La deuda exterior como mecanismo de transformación política, social y cultural: el mundo ibérico y el mediterráneo oriental, 1814-1914”. Ha formado parte del consejo de redacción de Agricultura y Sociedad y Revista Occidente, pertenecido a la Junta Directiva de la SEHA (Sociedad Española de Historia Agraria) y ha sido secretario adjunto de la Asociación Española de Historia Económica y editor de su Boletín. Forma parte del consejo asesor de la revista Zeitschrift für Agrargeschichte und Agrasoziologie y del consejo de redacción de Semata y de Illes i imperis. Ha sido director de la revista Historia Agraria. Desde 2015 dirige la revista de la Asociación Historia Contemporánea Ayer.

Cita sugerida: Carini, G. F. (2018). "No debemos abdicar de todo lo que ha avanzado la reflexión histórica en aras de la popularidad”: dinámicas historiográficas, relatos y contrarrelatos en España. Una entrevista a Juan Pan-Montojo. Trabajos y Comunicaciones (47), e050. https://doi.org/10.24215/23468971e050 
¿Cuáles fueron las aristas más destacadas del proceso de institucionalización de la historia a fines del siglo XX en España y en ese derrotero qué características asumió la consolidación de la historia económica y, puntualmente, de la historia agraria?.

Los historiadores que entre el franquismo final y la Transición accedieron a la Universidad, la generación de historiadores que podríamos llamar del 68, iniciaron cambios profundos en la historiografía española a partir del legado de algunas figuras aisladas de gran valía que habían llegado a las cátedras en los años cincuenta y sesenta. Esos cambios pueden entenderse como un proceso tardío de institucionalización, después del gran corte y marcha atrás que trajo consigo la victoria de la coalición de nacionalistas y católicos reaccionarios y de fascistas en 1939. Un primer elemento de la institucionalización de la historia fue la multiplicación de sus espacios académicos en el marco de las universidades. La historia general mantuvo y amplió su docencia vinculada a las Facultades de Geografía e Historia, algunas Facultades de Filosofía y Letra o de Profesorado mientras que la historia económica fue consolidándose de la mano del crecimiento de las Facultades de Ciencias Económicas y Empresariales que es donde se insertan los departamentos de historia económica. En general, el número de universidades en España creció de forma muy rápida en los años ochenta y primeros años de los noventa: pasamos de un número algo superior a 20 universidades al final del franquismo a las más de 80 que tenemos en la actualidad. Este es uno de los factores que explican la multiplicación del número de historiadores universitarios, en especial económicos aunque también de los generalistas. Además, creció un área más pequeña que es lo que se llama historia de los movimientos y del pensamiento social y político, que es otro campo del conocimiento construida en torno a las Facultades de Ciencias Políticas y Sociología. A estos procesos - crecimiento en el número de departamentos y áreas y por lo tanto de profesores - se sumó el desarrollo de asociaciones profesionales entre las que podemos mencionar la Asociación Española de Historia Económica, la Asociación de Historia Contemporánea, la Fundación de Historia Moderna, la Asociación de Historia Social, la Sociedad Española de Estudios Medievales, la Asociación de Historia Actual, el Seminario de Estudios de Historia Agraria que luego tomó el nombre de Sociedad Española de Historia Agraria y un sinfín de asociaciones más pequeñas. Ese es un segundo elemento de desarrollo institucional. Un tercer elemento ha sido la multiplicación de las revistas profesionales de historia con la aparición de muchas cabeceras y la progresiva estandarización de estas revistas a través su internacionalización, su inclusión en índices, etc. En cuarto lugar, habría que aludir a las convocatorias españolas y europeas de proyectos de investigación y de formación de redes. Estos son los aspectos más notorios de un proceso largo y complejo: se ha operado una institucionalización -amplia, generalizada- de la historia alrededor de las revistas, de las asociaciones, de los departamentos y de los grupos de investigación. Esta tendencia ha estado acompañada de una mayor especialización y diversificación de la historiografía, que a su vez ha traído consigo una cierta fragmentación de la disciplina de la historia. Cada vez existen más especialidades y los investigadores se mueven en un ámbito restringido y dialogan poco con lo que hacen sus colegas. Así, dentro del campo de la historia -en los últimos años- ha adquirido una visibilidad cada vez mayor la historia cultural, se ha renovado y crecido una historia política que nunca ha dejado de esta presente $\mathrm{y}$, al mismo tiempo, se ha producido una caída en importancia de la historia social más clásica y la adquisición de una clara autonomía de la historia económica, que ha pasado a estar situada cada vez en mayor medida al margen de la historia general. En este último ámbito se percibe una tendencia clara hacia el avance de la cliometría, como resultado de la interacción de la historia económica con una teoría económica dominada por el cuantitativismo. El resultado es falta de diálogo porque la historia general, con una cierta hegemonía de la historia cultural, ha pasado a utilizar un lenguaje a que a buena parte de los historiadores económicos y sociales les resulta bastante inhóspito y la historia económica con su tendencia al empleo de modelos econométricos ha pasado a ser incomprensible para mucha parte de los colegas que se dedican a la historia general. Esto, unido a la especialización, ha llevado a una cierta fragmentación, a un desmigajamiento de la historiografía. En este contexto, el mundo de la historia agraria-rural no es y es una excepción al tiempo. Ha experimentado un proceso idéntico de institucionalización por cuanto que ha constituido una organización propia y tiene su revista, así como seminarios y congresos con gran capacidad de convocatoria, premios anuales para las mejores publicaciones... Pero es algo excepcional, porque en su seno conviven 
profesionales dedicados a la historia económica y a la historia general tanto ontemporánea como moderna y medieval. En ese sentido, los agrarios han hecho un esfuerzo por intentar mantener un cierto diálogo entre investigadores que hacen las cosas con metodologías y estilos muy diferentes.

En ese proceso de institucionalización, ¿cuáles fueron los temas o problemas que contribuyeron a asentar la agenda de los historiadores?

En los años de la Transición, la gran pregunta para una parte de los historiadores era por qué la Guerra Civil, por qué el franquismo. Esta obsesión no solo alcanzaba a quienes se dedicaban a esos dos períodos, que en realidad eran relativamente pocos, sino que se manifestaba en el intento de explicar lo que se entendía que era una trayectoria excepcional de España en el marco europeo. Con un vocabulario marxista muy presente en la época, se buscaban respuestas a la tesis del supuesto fracaso de la revolución burguesa en España, a menudo presentada como un proceso en la vía prusiana, es decir, de una revolución que se saldó en beneficio de la nobleza porque la debilidad de la burguesía había hecho imposible una auténtica transformación. Se hablaba asimismo de una revolución inconclusa, vacilante, truncada que daba cuenta de una trayectoria muy peculiar del país, cuya prueba última eran el golpe de Estado en el año 1923, una transformación de una monarquía liberal que no podía evolucionar hacia una monarquía democrática, sino que pasó hacia una fase de monarquía autoritaria, luego a un paréntesis de república democrática y finalmente a la "anomalía” europea de la guerra civil y al franquismo. Esa obsesión por el recorrido especial de España, lo inundaba todo, hasta el punto de que algunos que investigaban el siglo XVIII se preguntaban cómo la crisis de la hegemonía hispana había incidido en la frustración cien años más tarde del triunfo de la burguesía. Pero tras el final del franquismo y a la par de la institucionalización tuvo lugar un proceso de diversificación de los debates y temas. En casi todos ellos se fue imponiendo a lo largo los años ochenta y noventa del siglo XX, sobre todo en estos últimos (cuando la consolidación democrática y la integración europea enterraron algunos fantasmas colectivos anteriores), el abandono de la idea de la excepcionalidad y el inicio de una visión global normalizada. Esa evolución acompañó a la relectura gradual del pasado en términos comparativos, posnacionales o transnacionales, con un énfasis creciente en los procesos regionales y globales. Este giro vino de la mano de una conciencia cada vez más plena del papel de la disciplina histórica como instrumento nacionalización en la contemporaneidad y a la necesidad de repensar la "historia-patria" en otros términos, incluso en abandonar la historia nacional como tal y hacer una historia de geografía variable según el objeto tratado. Diversificación de debates y globalización o inserción supranacional de la historiografía e incluso propuestas de hacer una historia posnacional. Pese a que, luego, ante la opinión pública, la voz de los historiadores haya seguido siendo demandada casi en exclusiva para atender problemas muy nacionales. Una de estas cuestiones políticas es lo que se llama globalmente memoria. Cuando en España se hace referencia a la cuestión de la memoria se hace alusión a la Guerra Civil y al primer franquismo, a las víctimas, a los victimarios, al tratamiento colectivo que este tema ha tenido, especialmente, durante la Transición. Sin dudas, esta cuestión está asociada a cambios generacionales: fue la generación de los nietos de las víctimas la que a finales del siglo XX y dentro de una tendencia mucho más universal de revisión de los traumas recuperó la preocupación por las historias personales y colectivas de los derrotados en la Guerra Civil e interpeló a los historiadores que no habían otorgado especial importancia a esa tarea. En el contexto de esos debates, en 2004, se impulsó un proyecto de ley de recuperación de la memoria histórica bajo el gobierno de Zapatero. Si bien era un proyecto extremadamente moderado, su presentación suponía implícitamente que el tipo de solución dada a la cuestión de las víctimas y los victimarios por la Transición había estado muy determinada por relaciones de fuerza coyunturalmente adversas y que resultaba necesario otro tipo de tratamiento a la represión. En torno a esto existe un amplio debate, hay quien dice que se intenta resucitar la división, el guerracivilismo, ganar en los libros de historia lo que no se puede ganar en las urnas etc. Este es uno de los ámbitos que está muy presente desde los años noventa hasta la fecha. El segundo ámbito en el que la opinión de los historiadores ha sido buscada es el de la construcción de las naciones y de las regiones. Este asunto ya había estado presente en la Transición pero ha adquirido un nuevo vigor posteriormente. Si la historia nacional ha mantenido su fuerza ha sido en parte alrededor de la necesidad u 
oportunidad de conjugarla en plural y de hacer a la vez historia nacional de Catalunya, historia nacional vasca, historia nacional gallega, historia nacional española, es decir, cómo ensamblarlas, qué formato darles, qué diálogo es posible. Cuestión que con la propia crisis territorial adquiere notable relevancia. La historia de la "nación española" y la historia de las otras "naciones", abandonadas como proyectos naturales e irreflexivos, han regresado por la vía de la reflexión sobre las identidades nacionales y el papel de la historiografía en su construcción.

En ese sentido, ¿cómo se han integrado esos relatos a la discusión historiográfica y qué rol han tenido los gobiernos autonómicos?

Es algo que está presente porque desde la Transición, desde la construcción del Estado de las autonomías, los gobiernos subestatales han financiado una historiografía propia, una historiografía regional/nacional. En algunos casos existía una tradición previa, en otros se trató de construcciones ex nihilo porque no existía ni siquiera el marco territorial, por tanto, había que construirlo, historizarlo. Esta financiación ha sido bastante "aséptica" en el sentido de que ha financiado obras de historia sobre esos espacios políticos sin exigir normalmente ningún tipo de lealtad ideológica a un proyecto nacionalista o regionalista: cosa distinta es que se apoyara en ocasiones diferencialmente a amigos políticos, algunos de los cuales podían compartir visiones cercanas a quienes se hallaban en el poder. La idea era hacer una historia "nacional/regional” por medio de la delimitación del objeto: el tomar un espacio determinado obliga a pensar en términos del mismo, pero no necesariamente siempre la historia regional o nacional es historia nacionalista (española, catalana, gallega, andaluza...). El grueso de la historiografía de ámbitos territoriales hispánicos, sub-estatales o estatal, no es necesariamente nacionalista, aunque sus autores deben prestar especial atención al riesgo de deslizarse en esa dirección.

En la coyuntura actual que se vive en España en torno a las reivindicaciones catalanas, ¿cuál es el papel de los historiadores o cómo se posicionan frente a los relatos históricos?

Hay muchos profesionales de la historia en las filas del nacionalismo catalán y del gallego y algo más reducida en las del vasco. Esa presencia es menor, aunque no esté ausente, en las filas de los nacionalismos españoles, que a menudo naturalizan su nación y por lo tanto no son conscientes de ser nacionalistas, incluso rechazan caracterizarse así. Como es sabido, la historia tiene un papel importante en la construcción de los imaginarios nacionales. No obstante, quienes más difunden determinadas visiones del pasado en clave nacionalista no son tanto los historiadores académicos, cuanto periodistas o aficionados. Son ellos los que con mayor fuerza construyen mitos en torno a -por ejemplo 1714- que es el momento de la Guerra de Sucesión, cuando los reinos de la antigua Corona de Aragón se alinearon - después de algunas vacilaciones iniciales - con el bando austracista, mientras que los reinos de la Corona de Castilla se alinearon con el bando borbónico, por lo que, en ocasiones, esta guerra es interpretada como una lucha entre España y Catalunya, una visión llena de anacronismos. También existen historiadores que tienden a interpretar la Guerra Civil como un conflicto entre Catalunya y España, cuando la Guerra Civil fue una guerra civil en Catalunya al igual que en el resto de España. En sentido contrario, hay historiadores que no se preocupan por entender la pluralidad de su objeto y generalizan sobre España y lo español. Hay además historiadores que recortan su objeto a la medida de determinados espacios políticos, siguiendo la estela de la disciplina nacionalizadora. Pero no se puede ignorar que la mayoría de los profesores de historia en las diferentes partes del país, en su práctica como historiadores, son bastantes conscientes del giro posnacional y, sean cuales sean sus posiciones como ciudadanos, tratan de construir relatos del pasado según las reglas de la disciplina y las tendencias historiográficas actuales. Los historiadores construimos relatos con fecha de caducidad y bajo el impacto de nuestras preocupaciones inmediatas pero podemos hacerlo con conciencia de nuestras limitaciones, abriendo nuestros textos a la crítica, insertándolos explícitamente en debates teóricos y políticos actuales y siendo los primeros en subrayar su contingencia y su apertura, o dejarnos llevar por 
un afán pseudo-científico que oscila entre la ingenuidad y la militancia en el peor sentido del término.

En ese sentido, ¿qué características asume en España el vínculo entre los profesionales de la historia y el ámbito de la comunicación pública de la ciencia?

Los historiadores deberían adoptar un papel más activo de comunicación pública de sus hallazgos. Por ejemplo, en Inglaterra todos los años se celebran unas semanas históricas, donde la gente se pone en contacto con aficionados, lectores, etc. Aquí se podría avanzar más en ese sentido y tratar de sustituir los relatos militantes del pasado por relatos complejos, autocríticos y abiertos. Aunque tampoco me hago muchas ilusiones de que una historiografía más reflexiva sea especialmente bien recibida. Los relatos que sirven para el combate político son relatos que los historiadores suministramos mal si somos historiadores honrados. Entonces es lógico que lo haga otra gente que está dispuesta a explicar realidades en blanco y negro, a explicar un "nosotros" tajante contra un "ellos" tajante, que está dispuesta a pasar de alto lo que tienen en común distintos procesos, que se muestra pronta a realizar un análisis estereotipado de la realidad. Nosotros podemos ocupar un lugar en ese campo de los relatos de combate, de hecho algunos colegas lo hacen, pero el grueso de los historiadores académicos, creo yo, y en esto me remito a una cierta concepción ética de nuestro papel, no debemos abdicar de todo lo que ha avanzado la reflexión de los propios historiadores, en los últimos sesenta años, sobre lo que hacemos y podemos hacer y hasta dónde llega nuestra capacidad de hacer relatos que nos ayuden a entender mejor el funcionamiento de las sociedades en todos los planos. No podemos volver a disfrazar con ropajes científicos narraciones cerradas y acríticas, en aras de la popularidad y para vender lo que la gente quiere oír.

\section{¿Cuáles son los posibles temas que pueden estar orientando una futura agenda de investigación en España?}

Hay un debate que imagino que va a estar muy presente que tiene que ver con la propia crisis de madurez del régimen político en España y esto puede llevar a que en términos muy hispano-españoles se multipliquen las reflexiones sobre la Transición como momento fundacional del régimen de la monarquía democrática actual. Esto va a ser un objeto de reflexión. Puedo suponer que según cómo evolucionen las relaciones interestatales dentro del ámbito de la Unión Europea y cómo avancen o no las reacciones nacionalistas con la reiteración de brexits en otros lugares o con la crisis del propio proyecto de nueva estatalidad que es la Unión Europea y según cómo se gestionen los nuevos retos de la globalización, los temas de la nación, el Imperio y la construcción estatal pueden tener una clara importancia en la agenda de investigación. En tercer lugar, considero que la historia medioambiental conectada con la historia agraria y también con otras historias va adquirir una importancia creciente tal cual se viene evidenciando desde los últimos años, dado que los procesos de cambio climático con efectos muy visibles están elevando la conciencia en nuestro entorno de la desertización, la multiplicación de procesos erosivos, la contaminación ambiental y de los mares, la pérdida de control sobre los alimentos... Sin duda, esto va a otorgarle una importancia especial. En cuarto lugar, las migraciones. Llama la atención cómo hemos podido estar tan ciegos los historiadores a este tema durante años. Incluso en países con procesos inmigratorios significativos como en Argentina, ha sido un tema bastante lateral hasta anteayer. Este un tema que va a tener una importancia creciente. En general, todo lo trasnacional, no solo los movimientos migratorios: la delincuencia transnacional, las redes religiosas transnacionales, las redes intelectuales transnacionales, los procesos de transferencia de objetos y conocimientos tecnológicos... creo que todo esto va a ir a más... Además, considero que el género está aquí para quedarse no tanto como especialidad en sí, aunque también, sino para teñir nuestro acercamiento a todos los demás objetos. De forma que el género va a ser una lente de nuestra forma de apreciación de la política del pasado no tanto por la ausencia muy presente de las mujeres en el espacio público cuanto por el recurso a las propias categorías de masculinidad y de feminidad para entender a los actores. Finalmente, nuevos sujetos y movimientos sociales van a pedir que rescatemos su pasado e introduzcamos la evolución histórica de los mecanismos de exclusión e inclusión que los han producido. 
Finalmente, ¿sobre qué temas y problemas se podría asentar una agenda común - en clave comparativa - entre Latinoamérica y España?

Los intercambios de personas, instituciones, obras en el ámbito hispano-latinoamericano ha sido enorme en las últimas décadas. Efectivamente, la historia comparada tiene mucho sentido en diferentes temporalidades. Por ejemplo, en el siglo XIX el período que va de la independencia a la construcción de los estados nacionales, que también es de construcción del estado nacional español, surgido la implosión del imperio, presenta importantes elementos para una comparación. Hasta la década de 1860 en la que en la mayoría de los países se puede comenzar a hablar de estados nacionales más o menos consolidados, ese período guarda muchas similitudes en ambos lados del Atlántico. En la posguerra de la II Guerra Mundial a mí me parece que las relaciones con Estados Unidos, con la potencia hegemónica, y lo que esas relaciones implican desde el punto de vista de agendas de desarrollo económico, de programas técnicos para la agricultura, de programas sociales y culturales, de la alianza entre regímenes autoritarios y EEUU, también son evidentes las similitudes entre la periferia latinoamericana y la periferia europea de la que España formaba parte. Esto es solo por citar dos temas, podríamos hablar también de la crisis del liberalismo, de la disyuntiva autoritarismo/democracias en los años 20-30, de los modelos de relaciones sociales y su estructuración, de los problemas estructurales y productivos de las agriculturas... Son infinitos los temas donde la historia comparada tiene un campo de aplicación muy grande, las posibilidades son enormes, con la ventaja de que tenemos un lenguaje común y que existe mucho interés en ambos lados del Atlántico por superar los marcos estrechos y poco fértiles a que da lugar una historiografía exclusivamente nacional.

\section{Notas}

* Esta entrevista fue realizada en el marco de un convenio de movilidad docente entre la Universidad Autónoma de Madrid y la Universidad Nacional de Río Cuarto. La misma se llevó a cabo en el Departamento de Historia Contemporánea el día 31 de octubre de 2017. 